\title{
10
}

\section{The development of performance auditing in Taiwan}

\author{
Kai-Hung Fang and Tsai-tsu Su
}

Performance auditing in Taiwan is at an early stage of development. Although the idea of doing an audit based on economy, efficiency and effectiveness criteria has been a feature of the audit law since 1972, the approach did not materialise until 2007, when Auditor-General ChingLong Lin took office. Since then, the National Audit Office (NAO) has made great efforts to promote performance auditing in Taiwan. For instance, the Guideline for the NAO on Performance Audit was published in 2009. It began the process of transferring more financial and human resources from traditional financial audits to performance audits (Lin 2012: 6-7).

However, the transition to performance audits is not an easy task. It involves not only training existing personnel and hiring new personnel with different professional backgrounds, but also fostering a new organisational culture in which NAO staff are open-minded and willing to adopt a new style of auditing. This is inevitably a slowly evolving process. This chapter describes this process. It begins by describing the context in which the NAO makes performance auditing an organisational priority, the efforts taken by the NAO to promote performance audits and its initial achievements. The chapter also discusses feedback from both $\mathrm{NAO}$ personnel and auditees. Finally, general discussion and conclusions about the development of performance auditing in Taiwan are presented. 


\section{The National Audit Office in transition}

The NAO is an independent government agency in Taiwan. As a branch of the Control Yuan, ${ }^{1}$ the Office of the Auditor-General, the head of the NAO, shall complete audits and submit annual audit reports to the Legislative Yuan after receiving the annual financial statements of the central government from the Executive Yuan. Due to the constitutional requirement to audit the central government's financial statements, the focus of the auditing has traditionally been placed on financial audits to ensure government agencies spend public funds in accordance with applicable laws and regulations.

The roots of performance auditing can be traced back to 1972, when the Audit Act 1925 was amended to add two new chapters that required the NAO to evaluate the efficiency and effectiveness of government agencies' budget execution and determine their financial accountabilities accordingly. However, it was not until 2007, when Lin became the auditor-general, that performance auditing became a priority. Lin (2012: 6) proclaimed that strengthening the evaluation of government performance and improving the efficiency and quality of public service provision should be core duties of the NAO (Xu 2009: 28). In 2012, he reaffirmed that the continuous improvement of performance auditing to enhance the value of public funds would be one of the primary objectives of his second term. ${ }^{2}$

The effort of the NAO to place more emphasis on performance auditing is further supported by trends in the international audit community. In the past decade, performance auditing has become increasingly common among supreme audit institutions (SAIs) (Colin and Wiggan 2010), which are the national authorities responsible for scrutinising budget execution and providing independent opinions on how government agencies use public funds. One of the drivers of this trend is the philosophy behind the 'maturity model of SAIs' suggested by the US Government Accountability Office (GAO) (see Figure 10.1).

1 The central government in Taiwan has five branches: the Executive Yuan, Legislative Yuan, Judiciary Yuan, Examination Yuan and Control Yuan. According to Article 104 of the Constitution, in the Control Yuan, there shall be an auditor-general who shall be nominated and, with the consent of the Legislative Yuan, appointed by the President of Taiwan. Article 105 states that the auditorgeneral shall, within three months of presentation by the Executive Yuan of the final accounts of revenue and expenditure, complete the auditing thereof in accordance with law and submit an audit report to the Legislative Yuan.

2 See the NAO's website: www.audit.gov.tw/files/11-1000-138.php (accessed 20 December 2016). 
The GAO (2007) argues that SAIs in industrialised countries have traditionally focused on oversight, as indicated at the bottom of the pyramid in Figure 10.1. This concentrates on the purchase of agency inputs and its legality and therefore is important for checks on waste, fraud and abuse. Nevertheless, although this oversight function can enhance financial transparency, combat corruption and ensure accountability, it is not sufficient on its own to help the government fulfil its policy objectives or take more timely and informed actions in an ever-changing society. By adopting performance auditing, SAIs may identify areas of waste and mismanagement that, if eliminated, would permit the same policy or program objectives to be achieved at less expense and areas where the same resources, if used differently, would produce greater value for the same cost (Allen and Tommasi 2001: 352). This type of value-added audit work makes up the middle layer of the pyramid in Figure 10.1 and is designed to provide insights to improve the efficiency and effectiveness of public expenditure.

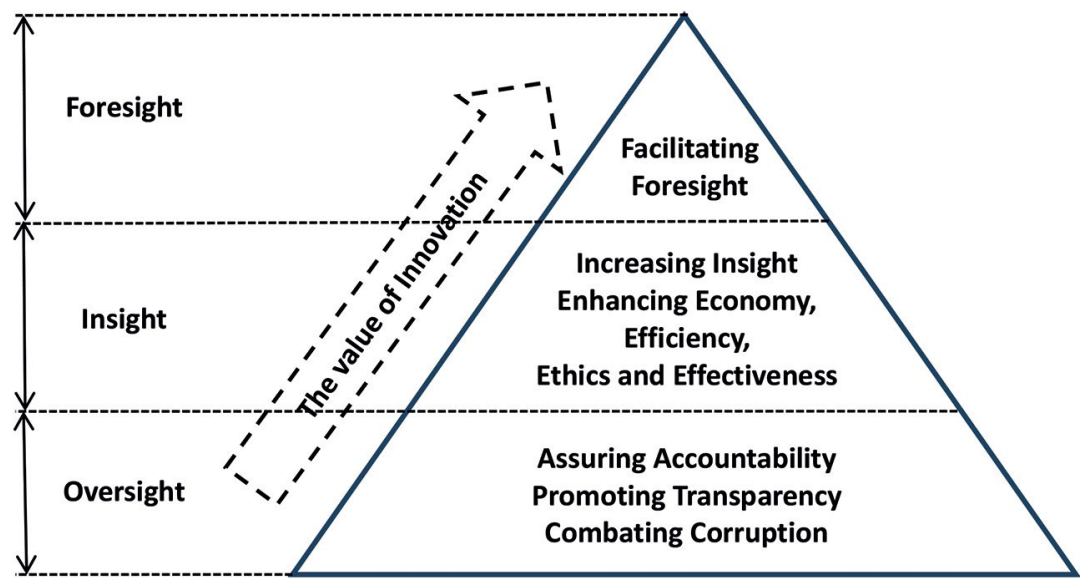

Figure 10.1 The maturity model of SAls

Sources: GAO (2007); NAO (various years(b): 7).

At the top of the pyramid, according to the GAO (2007), is a foresight function that more mature SAIs should be undertaking. A mature SAI is able to provide policymakers with foresight about emerging trends and help them grasp the long-term implications of current policy paths in a professional, evidence-based and nonpartisan manner. 
In summary, under the influence of the maturity model for SAIs, the goal of the NAO in the twenty-first century is to climb up the hierarchy of audit functions. The traditional financial audit concentrates on the basic audit function; its oversight activities deal with aspects of legality and aim to minimise corruption. The newly emphasised performance audits are aimed at both insight and foresight functions to further identify which spending programs or policies are effective and help government agencies take more timely and informed actions to maximise the value of public funds.

\section{Capacity-building in human resources}

Table 10.1 demonstrates that the NAO of Taiwan is a relatively stable organisation in terms of the number and average age of staff. From 2001 to 2015 , the total number of staff grew by only 2 per cent and the average age increased by less than one year. The NAO employed a group of welleducated professionals. According to the statistics released at the end of 2015, the majority of NAO staff were equipped with professional licences and 92 per cent had a bachelor's degree or above. However, most staff specialised in accounting or procurement regulation and, while familiar with financial audits, they had little experience in performance audits.

In addition, the total number of NAO staff has grown very slowly over the past decade (from 834 in 2001 to 853 in 2015) and, given restrictions on new recruitment imposed on the public sector, ${ }^{3}$ it is not expected to increase drastically in the coming years to cope with the additional workload derived from conducting performance audits. Hence, the only way to handle an increased workload is to initiate a capacity-building process so auditors are able to perform their jobs in a smarter and more productive way.

Table 10.1 Total number of NAO staff and their average age

\begin{tabular}{|l|c|c|}
\hline Year & Total number of staff & Average age of staff (years) \\
\hline 2001 & 834 & 42.9 \\
\hline 2010 & 823 & 43.3 \\
\hline 2011 & 836 & 43.2 \\
\hline 2012 & 815 & 43.3 \\
\hline 2013 & 855 & 42.9 \\
\hline
\end{tabular}

3 To control the number of government employees, the Legislative Yuan passed the 'Basic Law for Central Government Agency Manpower Allocation' in 2010. It imposes an upper limit on the number of civil servants in the executive branch. 


\begin{tabular}{|l|c|c|}
\hline Year & Total number of staff & Average age of staff (years) \\
\hline 2014 & 859 & 43.2 \\
\hline 2015 & 853 & 43.7 \\
\hline
\end{tabular}

Sources: Data collected from NAO (various years(a)).

Table 10.2 Educational level of NAO staff

\begin{tabular}{|l|c|c|c|c|c|}
\hline \multirow{2}{*}{ Year } & \multicolumn{4}{|c|}{ Education level } & \multirow{2}{*}{$\begin{array}{c}\text { Number of } \\
\text { licensed staff }\end{array}$} \\
\cline { 2 - 5 } & $\begin{array}{c}\text { High } \\
\text { school }\end{array}$ & Junior college & $\begin{array}{c}\text { Bachelor's } \\
\text { degree }\end{array}$ & $\begin{array}{c}\text { Graduate } \\
\text { degree }\end{array}$ & \\
\hline 2001 & $32(4 \%)$ & $208(25 \%)$ & $516(62 \%)$ & $78(9 \%)$ & 113 \\
\hline 2010 & $13(2 \%)$ & $107(13 \%)$ & $398(48 \%)$ & $305(37 \%)$ & 462 \\
\hline 2011 & $12(2 \%)$ & $93(11 \%)$ & $394(47 \%)$ & $337(40 \%)$ & 484 \\
\hline 2012 & $9(1 \%)$ & $84(10 \%)$ & $370(46 \%)$ & $352(43 \%)$ & 501 \\
\hline 2013 & $9(1 \%)$ & $77(9 \%)$ & $377(44 \%)$ & $392(46 \%)$ & 531 \\
\hline 2014 & $9(1 \%)$ & $70(8 \%)$ & $377(44 \%)$ & $403(47 \%)$ & 640 \\
\hline 2015 & $7(1 \%)$ & $62(7 \%)$ & $369(43 \%)$ & $415(49 \%)$ & 828 \\
\hline
\end{tabular}

Sources: Data collected from NAO (various years(a)).

To meet the challenge of evolving from financial to performance auditing, the NAO needs to build up its organisational capacity. One basic requirement is to have sufficient personnel with the knowledge and skills necessary to conduct performance audits. The NAO amended its Organic Act 1939 in 2010 to allow the recruitment of new auditors with policy analysis, public administration and management expertise. By the end of 2016, the NAO had recruited 52 auditors who were equipped to conduct performance audits to replace retirees and those who had left the NAO. This has brought greater diversity to the specialisation of employees in the NAO.

Furthermore, existing employees are encouraged to acquire performance auditing knowledge and skills through training and attending conferences. To this end, the NAO established a taskforce consisting of auditors skilled in quantitative analysis and social research methods. They introduced program evaluation techniques such as social surveys, in-depth interviews and focus groups for auditors who are in search of new analytical tools with which to evaluate the effectiveness and efficiency of policy programs (Liu 2014: 104). The NAO's training institute also devotes more resources to performance auditing, such as sending staff to the training programs held by the National Academy of Civil Service and to conferences held 
by professional auditing associations and academia (Lin 2012: 19). Approximately three-quarters of the training hours received by each NAO employee from 2011 to 2015 were related to performance auditing (see Table 10.3). It is evident that the NAO is working hard to provide opportunities for its staff to become more acquainted with performance auditing.

Table 10.3 Performance auditing-related training received

\begin{tabular}{|l|c|c|c|c|}
\hline $\begin{array}{l}\text { Fiscal } \\
\text { year }\end{array}$ & $\begin{array}{c}\text { Numbers } \\
\text { attending } \\
\text { training }\end{array}$ & $\begin{array}{c}\text { Number } \\
\text { of training } \\
\text { hours }\end{array}$ & $\begin{array}{c}\text { Training } \\
\text { hours per } \\
\text { employee }\end{array}$ & $\begin{array}{c}\text { Percentage of performance } \\
\text { auditing-related training } \\
\text { hours per employee in overall } \\
\text { training hours per employee }\end{array}$ \\
\hline 2011 & 2,260 & 36,767 & 53.83 & $74.00 \%$ \\
\hline 2012 & 2,087 & 35,486 & 53.12 & $72.26 \%$ \\
\hline 2013 & 2,130 & 38,118 & 74.27 & $72.37 \%$ \\
\hline 2014 & 2,684 & 46,762 & 65.77 & $82.70 \%$ \\
\hline 2015 & 3,618 & 47,750 & 67.54 & $79.51 \%$ \\
\hline
\end{tabular}

Sources: Data collected from NAO (various years(b)).

\section{Redirecting budgets to performance audits}

Along with improving human capital to build up organisational capacity, the NAO also triggered a process of allocating more budgetary resources to performance auditing-related activities. While spending related to performance auditing made up 45 per cent of the NAO's total budget in 2009, the remaining 55 per cent comprised spending related to financial auditing. The percentage of performance auditing-related budgets grew slowly but steadily from 2009 to 2015 (NAO various years(a)). In 2015, the budget allocated to performance audits exceeded the budget for financial audits for the first time at the NAO.

\section{Developing audit guidelines and manuals}

In the process of capacity-building to carry out more performance audits, the NAO developed several guidelines and manuals to assist frontline auditors. For instance, it released the 'Guideline for the NAO on Performance Audit' in 2009, and amended it several times to ensure it was at the cutting edge of development in the field of performance audit. The guideline is mostly based on the Performance Audit Guidelines: Key principles published by the International Organization of Supreme Audit Institutions (INTOSAI 2010). It highlights the values and rules of 
performance auditing, the importance of better communication between auditors and auditee agencies, the techniques for conducting interviews and social surveys, the requirement to summarise audit evidence and findings, provide background information in audit reports and the need for public access to performance audit reports (Lin 2013: 68). The 'Guideline for the NAO on Performance Audit' is the cornerstone of performance audit activities.

Based on the guideline, the NAO also published a series of manuals and best practices to further expand the knowledge base of its auditors, including a manual for selecting suitable performance audit targets using a risk-assessment approach (Lin 2012: 7; 2013: 66). Another guideline, titled Basics of Program Evaluation, was published, in 2014, to assist auditors to understand the complexity of public policy, to pay attention to the diversified needs of internal and external stakeholders and to facilitate more public debate on policy issues (Su and Wang 2015: 93-5).

\section{Outputs of performance auditing}

Although the transition from financial auditing to performance auditing is not an easy task, the NAO has steadily moved forward and made some achievements.

The NAO uses various indicators to measure its own annual performance (NAO 2016b). Among them, two indicators are closely related to performance auditing and are worth mentioning: the number of performance audit reports and the number of cases reported to the Control Yuan.

\section{The number of performance audit reports}

Following the adage 'what gets measured, gets done', the NAO designates the number of performance audit reports as one of its major indicators in its performance management system. This has introduced strong incentives for NAO employees to strive to reach their performance targets. As shown in Table 10.4, between 2010 and 2015, the actual number of performance reports completed by the NAO exceeded the performance objective each year, with the achievement rates ranging from 107 per cent to 124 per cent for the period examined. 
Table 10.4 Number of performance audit reports

\begin{tabular}{|c|c|c|c|}
\hline Fiscal year & Expected number/actual number & Total & Achievement rate \\
\hline \multirow[t]{2}{*}{2010} & Expected number & 153 & \multirow[t]{2}{*}{$107 \%$} \\
\hline & Actual number & 163 & \\
\hline \multirow[t]{2}{*}{2011} & Expected number & 140 & \multirow[t]{2}{*}{$114 \%$} \\
\hline & Actual number & 159 & \\
\hline \multirow[t]{2}{*}{2012} & Expected number & 142 & \multirow[t]{2}{*}{$111 \%$} \\
\hline & Actual number & 157 & \\
\hline \multirow[t]{2}{*}{2013} & Expected number & 121 & \multirow[t]{2}{*}{$114 \%$} \\
\hline & Actual number & 138 & \\
\hline \multirow[t]{2}{*}{2014} & Expected number & 118 & \multirow[t]{2}{*}{$124 \%$} \\
\hline & Actual number & 146 & \\
\hline \multirow[t]{2}{*}{2015} & Expected number & 119 & \multirow[t]{2}{*}{$111 \%$} \\
\hline & Actual number & 132 & \\
\hline
\end{tabular}

Source: NAO (various years(b)).

\section{The number of cases reported to the Control Yuan}

The number of performance audit reports discussed above is mostly a quantitative measure, which does not deliver much information about the quality of performance auditing. The indicator concerning the number of cases reported to the Control Yuan reveals relatively more information on the quality of performance audits conducted by the NAO.

According to Article 69 of the Audit Act, if the NAO considers an audited agency negligent of duty or suffering from major inefficiencies or ineffectiveness, it should report the case to the Control Yuan. The Control Yuan will then conduct further investigation to decide whether to exercise its power of censure on the audited agency. Because it may involve the exercise of censure power by the Control Yuan whenever an audited case is reported, the NAO, before making a decision to report to the Control Yuan, usually dedicates more effort to fully understand the operation of the audited agency, to communicate thoroughly with various stakeholders and to collect hard evidence in an objective manner. So, Article 69 of the Audit Act provides an effective tool for enhancing accountability in public governance.

As a result, the NAO assumes that the better the overall quality of performance audit, the higher is the number of cases of negligence of duty or poor performance reported to the Control Yuan, and vice versa. 
Figure 10.2 reveals the number of cases reported to the Control Yuan due to dereliction of duty or poor performance as specified in Article 69 of the Audit Act. It is striking to see that the number of cases reported increased drastically after the NAO began to focus more on performance audits in 2009. There were 36 reported cases in 2008, jumping to 95 cases in 2009 - an increase of 163 per cent. During the years without performance auditing (i.e. 1997-2008), the average number of cases reported to the Control Yuan due to dereliction of duty or poor performance each year was 21.6; the average increased to 80.3 cases for the period 2009-15, when the NAO was actively engaged in performance audits.

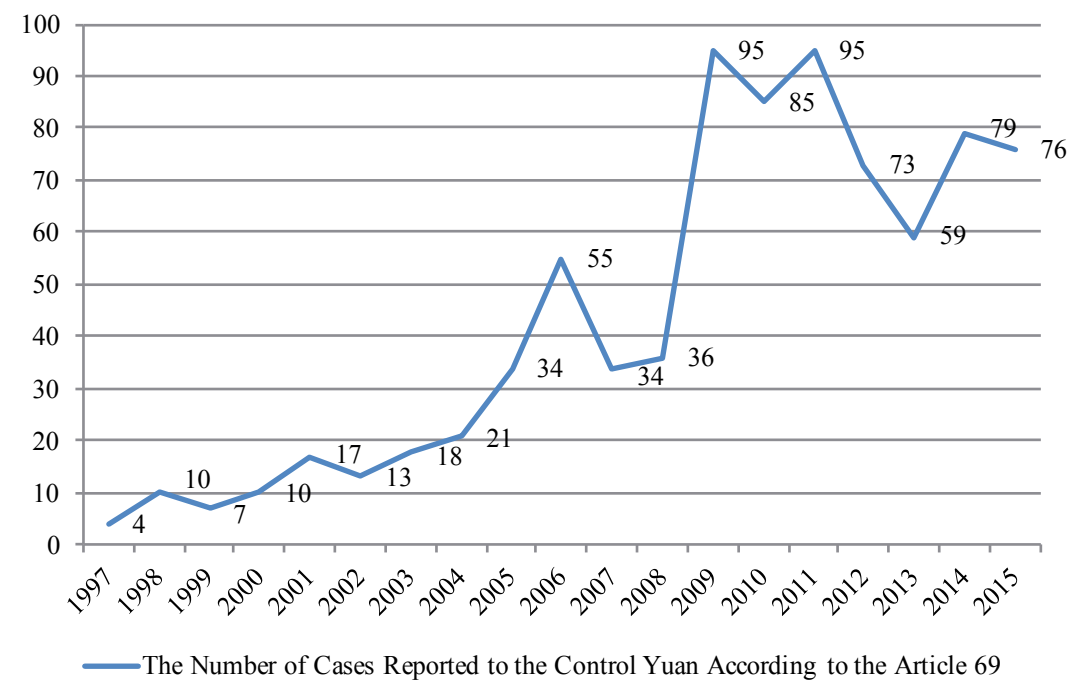

Figure 10.2 Number of cases reported to the Control Yuan due to negligence of duty or poor performance

Source: NAO (various years(a)).

\section{Feedback from NAO employees and auditees ${ }^{4}$}

Solid financial audits may keep government honest, yet they do little to encourage government agencies to fulfil their mission (Lee and Johnson 1998: 341). This is one of the reasons the NAO of Taiwan subscribes

4 The feedback described in this section is mostly based on the study by Su and Wang (2015) and five in-depth interviews by the authors with NAO employees in 2016. 
to the international trend in recent years towards focusing on performance audits. Nevertheless, conducting performance audits in the public sector is complex and challenging. Even though the NAO has a stable and welleducated taskforce, its conservative organisational culture ( $\mathrm{Su}$ and Fang $2009,2011)$ and ways of conducting audits are not easy to change.

\section{Auditors' opinions}

A study by Su and Wang (2015) finds that initial evaluations and feedback from NAO employees are generally positive. The majority of the auditors interviewed in the study are supportive of the NAO's transition towards performance auditing. Taiwanese auditors believe that performance auditing is an international trend that cannot be reversed. The auditors also believe that the publication of performance audit reports plays a vital role in the communication of essential information to public authorities and the general public, thus reducing the asymmetry of information in government performance. In fact, the performance audit reports released by the NAO have received more attention and publicity than the traditional financial audit reports, particularly during the election season. Legislators, electoral candidates and the media often use findings in audit reports to criticise incumbent candidates and the ruling party. To a certain extent, these performance audit reports have increased the influence of the NAO.

Many auditors point out that performance auditing applies new techniques and methodologies and is much more time-consuming ( $\mathrm{Su}$ and Wang 2015). Unlike performance auditing, the traditional financial auditing process is conducted using a prescribed checklist of steps to establish uniformity. While many auditors find performance auditing conceptually elusive and difficult to undertake, most agree that one of its unexpected benefits is that it expands the boundaries of their comfort zone and helps them gain a sense of greater self-achievement at work.

Apart from the benefits of performance auditing for the NAO and its auditors, the auditors interviewed in the study also highlighted limitations and challenges that need to be addressed ( $\mathrm{Su}$ and Wang 2015). First, most junior auditors complained that the time allowed for the audit team to complete a performance audit is usually insufficient to ensure the quality of their work. That is, in addition to conducting the performance audits assigned to the audit team, auditors are required to manage other duties as well. These duties may include conducting financial audits regularly, collecting data or preparing written reports for legislators when requested 
and investigating cases assigned by the Control Yuan. Moreover, the application of performance audit techniques and methodologies is new to most of the auditors and the scope of the performance audit is broader and more diversified compared with financial auditing, so they need more time to undertake this type of audit. Given the tight time frame imposed on completing an audit case at the NAO, auditors are under considerable pressure. Consequently, many of them fail to collect all the information and evidence needed to support their statements in the final reportfor example, external stakeholders' opinions relevant to the audited case are often ignored. In other words, the quality of audit results may be compromised due to the time constraints.

Several auditors perceive that the performance evaluation system inside the NAO may further compound the situation of 'quality versus quantity'. One of the implications of linking auditors' individual performance indicators to the production of performance audits is that there is an increase in competition at both the divisional level and the individual level at the NAO for the quantity of performance audits. It drives auditors towards short-term performance outputs rather than long-term performance results, such as improving the quality of performance audits or getting action-oriented audit recommendations, and this may be inconsistent with divisional goals.

The biggest concern for the NAO's auditors is how to avoid an infringement of executive power when conducting a performance audit. A traditional financial audit usually occurs after the government budget is executed. It then checks to ensure that the operations did not violate the budget plan or applicable laws and regulations. The main focus is on aspects of legality, and the major audit activities are to detect operational errors and abuses after the government program is implemented. This is the oversight function that lies at the base of the maturity model of SAIs (Figure 10.1), and the NAO's auditors feel comfortable in the exercise of their oversight duties. However, with regard to performance audits, the NAO aims to provide the executive with insightful advice and foresight to prevent inefficiency or ineffectiveness before it happens. Hence, it is likely that the policy recommendations written in a performance report will involve advice to the executive to alter the design or management of an audited program. Sometimes, it may even recommend the executive terminate an ineffective program while it is still at the implementation stage. On the surface, this is only 'advice' or a 'recommendation', yet audited agencies are obliged to explain to the $\mathrm{NAO}$ in a written report if they fail to follow 
the advice or recommendations. With this kind of power at hand, the auditors are worried about being accused of overstepping their authority (Su and Wang 2015). Moreover, they are afraid that, if the audited agency modifies the policy program as suggested by the NAO and it turns out to be a bad move, the auditors will have to share the blame with the agency, which may blur the accountability relationship.

\section{Auditees' opinions}

The feedback from public officials in the audited agencies is mixed. Some recognise that experienced auditors can provide insightful information to improve the execution of spending programs, particularly those that are jointly administered by several agencies. Because it is easy to miss seeing the wood for the trees when interagency coordination and planning are involved, boundary-spanning management is often a source of poor performance in the public sector. Several interviewees stated that experienced auditors without selfish parochialism might see the big picture better and help explain why some interagency programs and policies work, while others do not. This is why a holistic audit recommendation is regarded as helpful and is welcomed by the audited agency ( $\mathrm{Su}$ and Wang 2015: 101). This is also why the emphasis is increasingly placed on interagency programs in the implementation of performance auditing. For instance, in the selection of major performance audit targets in 2015, the NAO selected 25 policy programs. Among them, 19 were interagency programs (Su and Wang 2015: 94).

A less positive feeling towards performance auditing is related to the increased workload for the audited agencies. Although it is well known that performance audits use economy, efficiency and effectiveness criteria to assess the value and impact of government spending (Power 1997), there is no general agreement on a distinct and operational definition of a performance audit (English 2007; Gronlund et al. 2011). Hence, when the NAO extends its role from conducting financial audits to conducting performance audits in Taiwan, it expands the scope of audit from financial documents to agencies' policy planning processes, administrative procedures and performance results. As a result, the administrative burden of an audited agency to collect data and prepare summaries has increased tremendously (Su and Wang 2015: 101-2).

This may be justified if the extra workload resulting from performance audits brings in useful policy recommendations for the audited agencies. However, it is not unusual for the audited agencies to receive audit 
recommendations that are too vague to be truly useful. There are several reasons a performance audit report may have vague or infeasible policy recommendations. One reason is the lack of competence of the audit team, which creates an obstacle to producing quality recommendations. Another possible reason is a deliberate choice by the audit team to avoid the infringement of executive power and the responsibility that may come with it. As explained earlier, many auditors at the NAO are concerned about overstepping the NAO's authority with their audit recommendations. The best way for them to avoid this risk is to issue vague policy recommendations that cannot go wrong in any circumstances, which nevertheless may be perceived by auditees as a waste of their time.

Research for this study found that many auditees find the auditors' mindset and expectations disturbing. Theoretically, the ultimate goal for performance auditing is to provide insights and foresight for the executive to help them improve the economy, efficiency and effectiveness of government services. So a partnership, not an adversarial relationship, should exist between the auditors and the audited agencies. They share the same objective and should work together as a team to improve the delivery of government services. However, auditees complained that auditors often focused exclusively on finding problems. This is because an auditor is encouraged and expected by the NAO's incentive structure to detect inefficiency, ineffectiveness or misconduct in the service provision process. If an audit team fails to detect any 'faults' in the audited program, the audit operation is considered a 'failure' (Su and Wang 2015: 104-5). When an audit team conducts performance audits with this mindset, it is not difficult to imagine that audited agencies and auditors would develop an adversarial relationship, not a partnership. Hence, the auditees would not cooperate fully to provide all the necessary information for the purposes of program evaluation. As a result, the goal of enhancing the performance of audited agencies' spending programs will be compromised.

\section{Discussion and conclusions}

While financial audits focus on the purchase of agency inputs and their legality, performance audits evaluate the result of government programs and services based on their economy, efficiency and effectiveness. Performance audits are therefore often perceived to be synonymous with value for money (Power 1997). 
The Taiwanese Government today is facing a rapidly ageing population, rising public pension and healthcare costs and relatively low public revenue as a percentage of gross domestic product (GDP). ${ }^{5}$ Therefore, there is increased pressure on the financing and performance of government services and, as a consequence, expectations of the NAO's contribution are formidable. Thus, it is essential for the NAO to perform both financial audits and performance audits well if it wants to prove to the public that its audit work maximises value for public money and mitigates risks for society. Yet, while the NAO is experienced with financial audits, and some progress is being made on performance auditing, there is still a long way to go before it wins strong credibility in performance auditing. As a new approach for both auditors and audited agencies, performance audit activities at the $\mathrm{NAO}$ must cope with the following challenges.

First, it needs to overcome the problem of 'soft' or vulnerable evidence in the audit outcome. Compared with financial audits, which can usually objectively identify illegal conduct or irregularities in audit reports, performance audits present evidence that is more vulnerable to interpretation. That is, audited agencies may argue that evidence in audit reports is subjective or inconclusive since it is often derived from research methods such as in-depth interviews, opinion surveys or quantitative analyses. Unfortunately, these social science methods may lead to incorrect conclusions or inconclusiveness if used improperly. For instance, the audited agency may question the scientific rigour of evidence obtained through a social survey or it may question the opinions collected from stakeholders who are not 'representative' of all those who are involved. As a result, auditors at the NAO may find themselves devoting a lot of time and energy to learning new skills and improving the quality of evidence in a performance audit, yet being frustrated when the evidence obtained is questioned by the audited agency or the media.

The best solution to enhance the robustness of evidence presented and hence the credibility of audit reports is to improve the research design and to employ techniques and methodologies appropriately. For example,

5 The tax burden of taxpayers is usually evaluated by the ratio of total tax revenue to GDP. The ratios released by the Ministry of Finance of Taiwan for the years 2013-15 are 12 per cent, 12.3 per cent and 12.8 per cent, respectively. In comparison with other countries, Taiwan's taxpayers have a relatively low tax burden. For instance, in 2013, the tax burdens for Japan, Korea, France, Germany and the United States were between 17.9 per cent and 28.3 per cent. See the Ministry of Finance eTax Portal: www.etax.nat.gov.tw/etwmain/front/ETW118W/CON/417/5792586571079918315?tagCode= (accessed 1 January 2017). 
one approach is to increase the representation of stakeholders involved in the spending program in the performance audit process. The stakeholders of a policy program include policy decision-makers, program managers, target groups and other related individuals or groups. According to the INTOSAI (2016), maintaining good relationships with external stakeholders is important not only in the short-term perspective of getting access to information and achieving a good understanding of the audited program; it is equally important in the long-term perspective for the NAO to gain trust and credibility with stakeholders. Currently, due to the tight time constraints given to completing a performance audit, stakeholders outside the public sector are seldom invited to voice their opinions. Most opinions or evidence presented in the audit reports are obtained from staff working within the audited agencies. When evidence is not collected from all stakeholders involved in the design and implementation of a program, the findings can be biased and of little reference value. For instance, if external stakeholders are not consulted, it is difficult to assess rigorously and holistically the extent to which government programs reach their intended targets.

Another challenge that needs to be addressed is the insufficient incentive for interdivisional cooperation inside the NAO (Su and Wang 2015). More and more government spending programs are being implemented across organisational boundaries. To evaluate this type of policy program, the NAO must set up an interdivisional audit team to provide various types of domain knowledge and technical expertise needed to complete the audit. However, each division inside the NAO has its own turf and its own performance target. So, the organisational norm is that each division devotes most resources, including the best personnel, to its own audit cases, while dispatching fewer resources and less-experienced auditors to audit activities that involve interdivisional cooperation. Nevertheless, given the fact that more and more policy programs nowadays are of a crossboundary nature and are also more vulnerable to poor coordination and inefficiency, it is suggested that the NAO restructure its incentive system to effectively motivate individual auditors and each division to commit themselves more to interdivisional audit activities.

One more challenge for the NAO is to improve its communication with the public and the media, including to gradually increase the number of performance reports that are available for free download from its website and to publicise audit results in a more user-friendly format. To be fair, this is exactly what the NAO has been trying to do in recent years, although it 
is taking place slowly. For instance, the NAO completed 895 performance audits between 2010 and 2015 (see Table 10.4), but not all the results are available on the NAO's website. Only those audit reports that passed internal screening processes appear on the website. Only one performance audit report was released on the website in 2010 and no reports in 2011. The number gradually grew as time went by. Specifically, the number of performance audit reports appearing on the website increased from three in 2012, to 18 in 2013, 25 in 2014 and to 27 reports in 2015. The total number of performance reports available online by the end of 2015 was 74 , accounting for 8 per cent of the total number of reports completed (895 reports). It is expected that the number of reports posted to the NAO's website will continue to grow in the future.

In addition to posting more performance audit reports to its website, the NAO has also started to use social media such as YouTube and Facebook to publicise its audit results in a more user-friendly manner. ${ }^{6}$ Its efforts to communicate effectively with the public not only help to correct information asymmetry whereby the executive branch dominates the information available about government service provision, it also addresses the important accountability issue of 'who audits the auditors' (Porter et al. 2012). Taxpayers can look through audit reports and results to determine whether the NAO has done a good job in promoting maximum value for public funds.

Finally, the biggest challenge facing the NAO is how to change the mindset of auditors and build up mutual trust between the audit team and audited agencies. In retrospect, monitoring and holding audited agencies accountable have been the primary roles played by the NAO. However, if the purpose of conducting performance audits continues to be aligned with this traditional role (i.e. a focus on finding faults and holding the agencies accountable) then it is likely that the audit environment will not foster effective communication and mutual trust and thereby a culture of partnership between auditors and auditees. The audited agencies will not then cooperate willingly during the audit process and the information collected will likely be insufficient to produce credible or useful conclusions and recommendations for the auditee agencies to improve their efficiency and effectiveness. To help create an audit environment with relationships of trust, the auditor should follow two principles. One is to stick to the

6 For audit results on YouTube, see: www.audit.gov.tw/files/40-1000-15.php?Lang=zh-tw (accessed 1 February 2017). 
fundamental principle that quality should come first - that is, the focus of promoting performance audits should continue to be placed on quality instead of quantity. A large number of performance audits without robust findings or quality recommendations add little value to government service provision, and could even reduce administrative efficiency by diverting resources from implementing policies that meet citizens' needs to assisting audit activities.

The second principle for building trust is to pay more respect to executive power. For example, the audit team should frame the wording of their audit opinions in a way that provides helpful suggestions or advice, rather than instructions. The audited agencies should also be given the opportunity to comment, not only on the material facts of the performance audit report, but also on the conclusions and recommendations therein. In addition, unless required by law or regulation, the executive agency that is responsible for the final results of its government programs should have the discretion to determine whether or not to adopt audit recommendations. This is the case in many industrialised countries such as Australia and the United States.

In other words, it is suggested that, with respect to its performance audit activities, the NAO of Taiwan should take on the role of an independent management consultant to give advice to help the executive branch improve public services, and leave the role of public accountant or judge to the field of traditional financial audit. ${ }^{7}$ As public accountants, auditors must produce reports aimed at enhancing the transparency and accountability of executive agencies, while, as a judge or magistrate, the audit organisation has the authority to pronounce on the legality of the actions of executive agencies and give decisions on how well they conform to requirements (Pollitt 2003: 164). Both roles are consistent with the oversight duties and meet the stringent requirement of government accountability. Conversely, when confining the institutional role of the $\mathrm{NAO}$ as a management consultant during the process of performance auditing, its main objective is to provide insights and foresight for the

7 According to Pollitt (2003: 164), performance auditing involves four alternative roles, which are not perfectly reconcilable with one another. They are: '(a) As a public accountant, producing reports aimed principally at enhancing the accountability and transparency of public bodies. (b) As a management consultant, giving help and advice to public bodies to help them improve themselves. (c) As a scientific or research-based organization, unearthing, creating and disseminating new, scientifically tested knowledge about how public programs and projects are working. (d) As a judge or magistrate, pronouncing on the legality of the actions of public bodies and giving decisions on how far they conform to formal procedures and requirements.' 
executive branch as an equal partner; therefore, the influence of the NAO hinges not on formal authority or law, but on the technical capacity of its staff and effective communication with its clients and stakeholders.

\section{References}

Allen, R. and D. Tommasi. 2001. Managing Public Expenditure: A reference book for transition countries. Paris: OECD Publishing.

Colin, T. and J. Wiggan. 2010. 'The public value of the National Audit Office'. International Journal of Public Sector Management 23(1): 54-70. doi.org/10.1108/09513551011012321.

English, L. M. 2007. 'Performance audit of Australian public private partnerships: Legitimizing government policies or providing independent oversight?' Financial Accountability and Management 23(3): 313-36. doi.org/10.1111/j.1468-0408.2007.00431.x.

Government Accountability Office (GAO). 2007. Enhancing Performance, Accountability, and Foresight. GAO-07-165CG. Washington, DC: GAO.

Gronlund, A., F. Svardsten and P. Ohman. 2011. 'Value for money and the rule of law: The (new) performance audit in Sweden'. International Journal of Public Sector Management 24(2): 107-23. doi.org/10.1108/09513551111109026.

International Organization of Supreme Audit Institutions (INTOSAI). 2010. Performance Audit Guidelines: Key principles. ISSAI 3100. Vienna: INTOSAI.

International Organization of Supreme Audit Institutions (INTOSAI). 2016. Guidelines on Central Concepts for Performance Auditing. ISSAI 3100. Vienna: INTOSAI.

Kuo, T.-J. and Z.-Y. Xu. 2013. 'The study on establishing performance management system at auditing offices'. Government Audit Journal 33(2): 92-100.

Lee, R. D., jr, and R. W. Johnson. 1998. Public Budgeting System. 6th edn. Frederick, MD: Aspen Publishers.

Lin, C.-L. 2012. 'The status and prospects of promoting government performance auditing'. Internal Auditor 78: 5-13. 
Lin, C.-L. 2013. 'The role and function of government audit in public governance'. Public Governance Quarterly 3: 58-73.

Liu, Y.-C. 2014. 'The development of government performance auditing in Taiwan'. Government Audit Journal 35(1): 95-107.

National Audit Office of Taiwan (NAO). Various years(a). Government Annual Audit Report. Taipei: NAO.

National Audit Office of Taiwan (NAO). Various years(b). NAO's Annual Performance Report. Taipei: NAO.

National Audit Office (NAO). 2009. Guideline for the NAO on Performance Audit. Taipei: National Audit Office.

National Audit Office (NAO). 2014. Basics of Program Evaluation. Taipei: National Audit Office.

Pollitt, C. 2003. 'Performance audit in Western Europe: Trends and choices'. Critical Perspectives on Accounting 14(1): 157-70. doi.org/ 10.1006/cpac.2002.0521.

Porter, B., C. Ó hÓgartaigh and R. Baskerville. 2012. 'Audit expectationperformance gap revisited: Evidence from New Zealand and the United Kingdom'. International Journal of Auditing 16(2): 101-29. doi.org/10.1111/j.1099-1123.2011.00443.x.

Power, M. 1997. The Audit Society: Rituals of verification. Oxford: Oxford University Press.

$\mathrm{Su}$, T.-T. and K.-H. Fang. 2009. Strategies for Restructuring Audit Organizations in Taiwan. Taipei: NAO.

Su, T.-T. and K.-H. Fang. 2011. Strategic Management and Performance Evaluation System in Audit Organization. Taipei: NAO.

Su, T.-T. and H.-W. Wang. 2015. Strategies to Promote Program Evaluation in Audit Organizations. Taipei: NAO.

Wang, Y.-S. 2002. 'The study on enhancing government audit functions'. Audit Journal 22(4): 7-21.

Xu, Z.-Y. 2009. 'The status and prospects of performance auditing'. Government Audit Journal 29(4): 25-35. 
This text is taken from Value for Money: Budget and financial management reform in the People's Republic of China, Taiwan and Australia, edited by Andrew Podger, Tsai-tsu Su, John Wanna, Hon S. Chan and Meili Niu, published 2018 by ANU Press, The Australian National University, Canberra, Australia. 